\title{
Long-Term Efficacy and Safety of Pimecrolimus Cream $1 \%$ in Adults with Moderate Atopic Dermatitis
}

\author{
Michael Meurer ${ }^{\mathrm{a}}$ Manige Fartasch ${ }^{\mathrm{b}}$ Gisela Albrecht ${ }^{\mathrm{c}}$ Thomas Vogt ${ }^{\mathrm{e}}$ \\ Margitta Worm ${ }^{d}$ Thomas Ruzicka ${ }^{f}$ Peter Josef Altmeyer ${ }^{g}$ Dirk Schneider ${ }^{i}$ \\ Gottfried Weidinger $^{h}$ Matthias Braeutigam ${ }^{\text {h }}$ \\ for the CASM-DE-01 Study Group
}

aHautklinikum, Universitätsklinikum der TU, Dresden, b Dermatologische Klinik und Poliklinik, Universitätsklinikum, Erlangen, 'Dermatologische Klinik, Vivantes Krankenhaus Spandau, und dHautklinik, Charité Mitte, Humboldt-Universität, Berlin, e Dermatologische Klinik, Universitätsklinikum, Regensburg,

${ }^{f}$ Hautklinik, Universitätsklinikum, Düsseldorf, 9St.-Josef-Hospital, Klinikum der Ruhr-Universität, Bochum, and ${ }^{h}$ Clinical Research, Novartis Pharma GmbH, Nürnberg, Germany; iClinical Development, Novartis Pharma AG, Basel, Switzerland

\section{Key Words}

Pimecrolimus cream $1 \% \cdot$ Elide $^{\circledR}$. Atopic dermatitis, moderate disease - Eczema · Long-term management • Topical corticosteroids

\begin{abstract}
Background: Pimecrolimus cream $1 \%$ is a non-steroid, selective inflammatory cytokine inhibitor indicated for atopic dermatitis (AD). Objective: To compare the safety and efficacy of pimecrolimus cream $1 \%$-based treatment versus conventional therapy in adults with moderate AD. Methods: Patients were randomized to receive pimecrolimus cream $1 \%(n=62)$ or vehicle $(n=68)$ at the first signs/symptoms of $A D$, for 24 weeks as required. $A$ moderately potent topical corticosteroid (prednicarbate $0.25 \%$ cream) was allowed in both groups to treat flares. Results: Corticosteroids were required on fewer days in the pimecrolimus group, compared with the vehicle group $(9.7$ vs. $37.8 \%$, $p<0.001)$. Furthermore, $59.7 \%$ of pimecrolimus-treated patients experienced no flares
\end{abstract}

\section{KARGER}

Fax +41613061234

E-Mail karger@karger.ch

www.karger.com

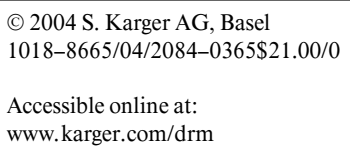

during the study period, compared with $22.1 \%$ of vehicle-treated patients $(p<0.001)$. Pimecrolimus cream $1 \%$ was well tolerated throughout the study. Conclusion: For adults with moderate $A D$, pimecrolimus cream $1 \%$ is well tolerated, reduces the incidence of flares, reduces/ eliminates corticosteroid use, improves long-term disease control and enhances the patients' quality of life.

Copyright $\odot 2004$ S. Karger AG, Basel

\section{Introduction}

Atopic dermatitis (AD) is a chronic, highly pruritic skin disorder, which is common in both children and adults [1]. Historically, the management of $\mathrm{AD}$ has been based on the exclusion of allergens and atopic triggers, the use of emollients to maintain skin hydration and topical corticosteroids to treat disease exacerbations [2]. This paradigm is limited, however, as topical corticosteroids cannot be used continuously without the risk of sideeffects, of which the most important is skin atrophy [3, 4]. 
Corticosteroids are therefore used reactively, with treatment typically initiated only when a severe exacerbation has developed. Many patients also have negative perceptions about the use of topical corticosteroids [5, 6]. Consequently, $\mathrm{AD}$ may be inadequately controlled in many patients.

Pimecrolimus is an anti-inflammatory macrolactam derivative, specifically developed for the treatment of inflammatory skin diseases. Pimecrolimus selectively inhibits the release of pro-inflammatory mediators from activated $T$ cells, via the inhibition of calcineurin [7-9]. In higher doses, pimecrolimus can also inhibit the release of pro-inflammatory cytokines from mast cells [10]. These actions inhibit the cascade of local immune and inflammatory responses central to the pathogenesis of both acute and chronic AD. However, because the effects of pimecrolimus are highly specific and cell selective, the drug does not produce atrophogenic or other steroid-specific side-effects and can, therefore, be used safely for extended periods $[8,11,12]$. This safety profile supports a proactive management model, in which treatment is initiated at the first sign of an incipient flare, to prevent progression to full flare.

To test the new, pimecrolimus-based approach to $\mathrm{AD}$ management in adult patients, a large, randomized, 6month study comparing the traditional and novel management models was conducted [13]. The study demonstrated that pimecrolimus cream $1 \%\left(\right.$ Elidel $\left.^{\circledR}\right)$ was a highly effective treatment for $\mathrm{AD}$, substantially reducing the number of flares and thereby reducing or eliminating the need for corticosteroids. The first report from this study included patients with a range of disease severities at baseline, including both moderate and severe disease [13]. However, pimecrolimus cream $1 \%$ is only indicated in patients with mild to moderate disease; therefore, an analysis was conducted in which patients with severe $\mathrm{AD}$ were excluded, to provide a clearer indication of the effects of treatment in the context of the current drug labelling. Here, we report the results of this 6-month study in adult patients with moderate $\mathrm{AD}$ at baseline.

\section{Patients and Methods}

\section{Study Design}

This was a randomized, double-blind, parallel-group, multicentre study conducted at 16 centres in Germany. Patients were recruited between September 1999 and June 2000. Patients were randomized $1: 1$ to receive 24 weeks of treatment with either pimecrolimus cream $1 \%$ or a corresponding vehicle cream; both groups used emollients and topical corticosteroids as directed in the protocol and described in detail below.
Patients were randomly assigned to treatment using computergenerated lists. To maintain the study blind, the vehicle cream used in the control group had an identical appearance and odour to pimecrolimus cream $1 \%$. Blinding was strictly maintained at all times for all participating patients, healthcare professionals and site-monitoring and data management personnel.

The study was performed according to Good Clinical Practice for trials on medicinal products in the European Union and the Declaration of Helsinki on medical research in humans. All patients gave written, informed consent, and the institutional review board and ethics committees of each participating centre approved the study protocol.

\section{Patients}

All patients had a clinical diagnosis of $\mathrm{AD}$, according to the criteria of Rajka [14]. Patients were required to have AD affecting at least $5 \%$ of their total body surface area. The group of patients described in this report had moderate disease at baseline, defined by an Investigators' Global Assessment (IGA) score of 3.

Patients were excluded from participation if they had received systemic corticosteroids, immunosuppressants, cytostatics, psoralen plus UVA (PUVA) or high-dose UVA within the previous 3 months, systemic corticosteroids for conditions other than $\mathrm{AD}$ within the previous month, or topical therapies for $\mathrm{AD}$ within the previous 2 weeks. Other exclusion criteria were: pregnancy; lactation; women of child-bearing age not using contraception; severe concurrent allergic diseases; diseases associated with malignancy or immunosuppression; the presence of skin conditions that could affect the study treatment; active skin infections requiring treatment with a prohibited medication; active herpes simplex infection, and the need for potent topical corticosteroids to control AD.

\section{Study Interventions}

Patients applied the study medication (pimecrolimus cream 1\% or corresponding vehicle) twice daily to all affected areas. Treatment was initiated at the first signs or symptoms of $\mathrm{AD}$ (including pruritus or erythema) and continued until complete clearance. Emollients were applied to the skin after application of the study medication. Prednicarbate cream $0.25 \%$ (Dermatop ${ }^{\circledR}$ ), a moderately potent topical corticosteroid, was given to patients in both groups if, despite treatment with the study medication, the itching or pronounced clinical signs of $\mathrm{AD}$ (severe erythema, excessive scratch marks or oozing/ crusting) became unacceptable to the patient. Prednicarbate cream $0.25 \%$ was used twice daily for a maximum of 7 days, followed by a reduction to once daily treatment for 7 days or until clearance of the signs of $\mathrm{AD}$ was achieved. After steroid treatment, patients were required to use the study medication for 7 days to treat any residual disease and/or prevent disease rebound. Patients were able to use bland emollients freely throughout the study, but no other active treatment for $\mathrm{AD}$ was permitted, with the exception of the antihistamine cetirizine, which could be taken at a constant dose throughout the study.

\section{Assessments}

Patients were assessed at screening ( 2 weeks to 2 days prior to randomization), at baseline and weeks $1,3,6,12$ and 24 . An additional telephone contact was made during weeks 9 and 18. Unscheduled visits were made in the event of flares.

The primary efficacy endpoint was the percentage of days on which a topical corticosteroid was used. This endpoint provided a 
method of quantifying the ability of the pimecrolimus-based treatment to prevent flares of $\mathrm{AD}$ requiring corticosteroid treatment. Secondary efficacy endpoints included: the number of disease flares; the time to first flare; IGA score; Eczema Area and Severity Index (EASI); pruritus rating, and the patients' self-assessment score.

A flare was defined as a period of at least 3 consecutive days in which topical corticosteroid application was considered necessary by the investigator. The pruritus rating was a 4-point score, self-assessed by patients: $0=$ none, $1=$ mild, $2=$ moderate, $3=$ severe. Similarly, the patients' self-assessment of disease control was scored on a 4 point scale: $0=$ complete disease control, $1=$ good disease control, 2 = limited disease control, $3=$ uncontrolled disease.

Prior to the study, all investigators were required to undergo training in IGA and EASI assessments. The IGA is a static (i.e. no reference to baseline state), 6-point measure of disease severity based on an overall assessment of skin lesions. An IGA score of 0 (clear) corresponds to no inflammatory signs of $\mathrm{AD}, 1$ (almost clear) to just perceptible erythema and just perceptible papulation/infiltration, 2 (mild) to mild erythema and mild papulation/infiltration, 3 (moderate) to moderate erythema and moderate papulation/infiltration, 4 (severe) to severe disease with severe erythema and severe papulation/infiltration and 5 (very severe disease) to severe erythema and severe papulation/infiltration with oozing/crusting. An IGA score of 0 (clear) to 2 (mild disease) at the study endpoint was categorized as treatment success.

The EASI is a composite score that assesses the severity of erythema, infiltration/papulation, excoriation and lichenification in the 4 body regions (head/neck, trunk, upper limbs and lower limbs) as well as the surface area involvement. The results from different body regions are adjusted by age and combined to yield a score of $0-72$ [15].

The impact of treatment on quality of life was assessed using two instruments: the Quality of Life Index for Atopic Dermatitis (QoLIAD) and the Dermatology Life Quality Index (DLQI). The QoLIAD is a 25-item questionnaire, with each question requiring an answer of either yes (score $=1$ ) or no $($ score $=0)$. The QoLIAD is expressed as a percentage of the maximum possible score of 25; the higher the score, the greater the impairment of quality of life [16]. The DLQI is a 10-part questionnaire relating to symptoms and perception of disease, daily activities, work or school, personal relationships, leisure and consequences of treatment, with each question scored $0-3$. The score is expressed as a percentage of the maximum possible score of 30 and, similarly to the QoLIAD, the higher the score, the greater the impairment of quality of life [17].

Adverse events were recorded throughout the study. Physical examination, standard haematology and blood chemistry tests were performed at regularly scheduled intervals. Patients also completed diaries, in which they recorded medication use, changes in medical condition and pruritus score from 0 (none) to 4 (very severe).

\section{Statistical Analysis}

Only patients with an IGA score of 3 (moderate disease) at baseline were included in the analysis. Statistical analyses were performed on the intention-to-treat population, defined as all randomized patients to whom the study medication was dispensed. The last observation carried forward method was used to impute data for all missing endpoints. The primary efficacy endpoint was the percentage of days on which corticosteroid was administered, i.e. the number of days on which steroid was taken, expressed as a percentage of the total number of days from week 0 to week 24. Data from patients

Long-Term Safety and Efficacy of

Pimecrolimus Cream 1\% who withdrew from the study due to lack of efficacy or adverse events were analysed as though the patients had used topical corticosteroids for the remainder of the study. The 2 treatment groups were compared using the Wilcoxon rank sum test at a significance level of 5\%.

In secondary efficacy analyses, tests were used in an exploratory fashion. Treatment groups were compared using analysis of covariance (ANCOVA), the Wilcoxon rank sum test, Fisher's exact test or logistic regression, as appropriate. Time to first flare data were analysed using survival analytical methods (log rank test). The effect of baseline variables on time to first flare was investigated by fitting a Cox proportional hazards model, including the following factors: centre, baseline IGA, baseline EASI, age category and treatment group. The EASI was analysed using ANCOVA.

Quality of life was assessed at baseline, week 6 and week 24, with summary statistics calculated at each of these time points for each treatment group. Safety analysis was descriptive, with group comparisons for adverse events made using Fisher's exact test.

Differences between groups in laboratory parameters were compared using the Wilcoxon rank sum test.

\section{Results}

\section{Patients}

Of the 192 patients randomized for treatment, 130 had moderate disease at baseline, as defined by an IGA score of 3 . A total of 62 patients with moderate disease at baseline were randomized to pimecrolimus cream $1 \%$-based treatment, and 68 were randomized to conventional treatment (control group). A flow diagram of patient randomization and treatment outcomes is shown in figure 1, and the patients' demographics and clinical characteristics are summarized in table 1.

Table 1. Baseline demographics and clinical characteristics

\begin{tabular}{lcc}
\hline & $\begin{array}{l}\text { Pimecrolimus } \\
\text { cream } 1 \%(\mathrm{n}=62)\end{array}$ & $\begin{array}{l}\text { Control } \\
(\mathrm{n}=68)\end{array}$ \\
\hline $\begin{array}{l}\text { Age, years } \\
\quad \text { Mean } \pm \text { SD }\end{array}$ & \\
$\quad$ Median & $29.2 \pm 9.7$ & $31.4 \pm 10.0$ \\
$\quad$ Range & 27.0 & 29.0 \\
Gender, $\mathrm{n}$ & $18-65$ & $18-66$ \\
$\quad$ Male & $25(40.3 \%)$ & $25(36.8 \%)$ \\
$\quad$ Female & $37(59.7 \%)$ & $43(63.2 \%)$ \\
Total body surface area affected, \% & \\
$\quad$ Mean \pm SD & $13.9 \pm 5.8$ & $12.7 \pm 5.8$ \\
$\quad$ Range & $6.0-30.0$ & $5.0-27.0$ \\
EASI & & \\
$\quad$ Mean \pm SD & $9.3 \pm 3.9$ & $8.6 \pm 4.0$ \\
$\quad$ Range & $2.0-20.9$ & $2.6-19.4$ \\
\end{tabular}

$\mathrm{SD}=$ Standard deviation 
Fig. 1. Flow diagram of patient randomization and treatment outcomes. ITT $=$ Intention to treat.

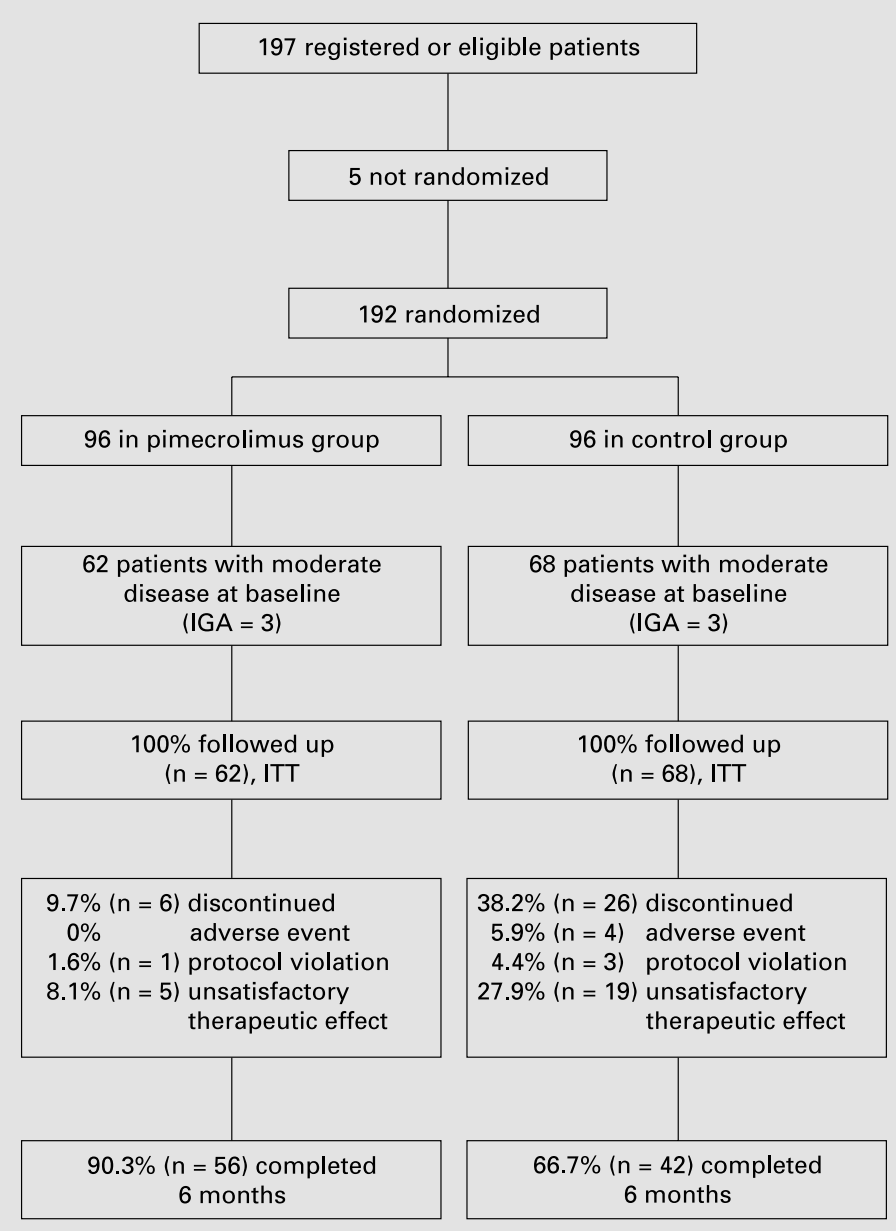

There were no significant demographic or clinical differences between the 2 groups at baseline, and the age distributions and gender ratios were similar. All patients except 2 (both in the control group) were Caucasian. The mean body surface area affected by AD at baseline was approximately $14 \%$ in the pimecrolimus group and $13 \%$ in the control group. The median EASI was 8.8 for both the pimecrolimus group and control group, which is consistent with the classification of these patients by the IGA score as having moderate disease.

In total, $38.2 \%$ of patients in the control group discontinued early, compared with only $9.7 \%$ of patients in the pimecrolimus group $(p<0.01)$. The principal reason for this difference was the greater number of patients in the control group who discontinued treatment due to an un- satisfactory therapeutic effect (27.9 vs. $8.1 \%$, respectively; $p=0.01)$.

\section{Efficacy}

Treatment with pimecrolimus cream $1 \%$ resulted in a significant reduction in the percentage of days on which patients used topical corticosteroids. In total, 37 patients (59.7\%) in the pimecrolimus group did not use corticosteroids at all during the study, compared with 17 patients $(25.0 \%)$ in the control group. During the 6 months of the study, patients in the pimecrolimus group used corticosteroids for a mean of $9.7 \%$ of study days, compared with $37.8 \%$ of study days in the control group ( $p<0.001$ ). Consistent with these findings, the number of flares was significantly lower in the pimecrolimus group (table 2), 


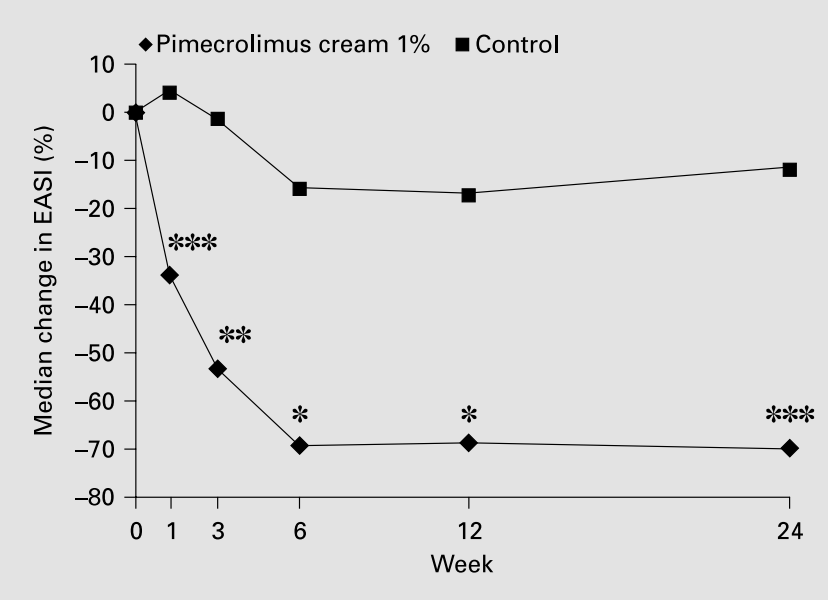

Fig. 2. Median percentage change in EASI over 24 weeks. ${ }^{* * *} \mathrm{p}<$ $0.0001,{ }^{* *} \mathrm{p}<0.001,{ }^{*} \mathrm{p}<0.01$ (pimecrolimus vs. control).

compared with the control group. In total, 37 patients (59.7\%) who were treated with pimecrolimus cream $1 \%$ had no flares during the course of the study, compared with 15 patients $(22.1 \%)$ in the control group $(\mathrm{p}<0.001)$. The mean number of flares among patients in the pimecrolimus group was $1.0 \pm 1.5$, compared with $2.3 \pm 2.5$ in the control group $(\mathrm{p}<0.001)$.

Treatment with pimecrolimus cream $1 \%$ produced a rapid improvement in the signs and symptoms of $\mathrm{AD}$, which was sustained throughout the course of the study. The median EASI for the pimecrolimus group decreased during the course of the study from 8.8 to 2.1 , a reduction of $71.1 \%$; however, it changed far less in the control group, decreasing only from 8.8 to 5.2 , a reduction of $11.6 \%(\mathrm{p}<0.0001)$ (fig. 2). Treatment success, defined as an IGA score of $0-2$, was achieved in 50 patients $(80.6 \%)$ in the pimecrolimus group, compared with 25 patients $(36.8 \%)$ in the control group $(\mathrm{p}<0.001)$.

Pruritus improved rapidly following treatment with pimecrolimus cream $1 \%$. On the second day of treatment, the percentage of patients with a pruritus score of 0 (none) or 1 (mild) was already significantly higher in the pimecrolimus group than in the control group $(\mathrm{p}<0.01)$ (fig. 3). By week 24, a total of 43 patients $(69.3 \%)$ in the pimecrolimus group reported no or mild pruritus, compared with 24 patients $(35.3 \%)$ in the control group $(\mathrm{p}<0.001)$. Results of the patients' self-assessment showed that 45 patients $(72.6 \%)$ in the pimecrolimus group and 26 patients $(38.2 \%)$ in the control group considered disease control to be good or complete by week $24(\mathrm{p}<0.001)$.

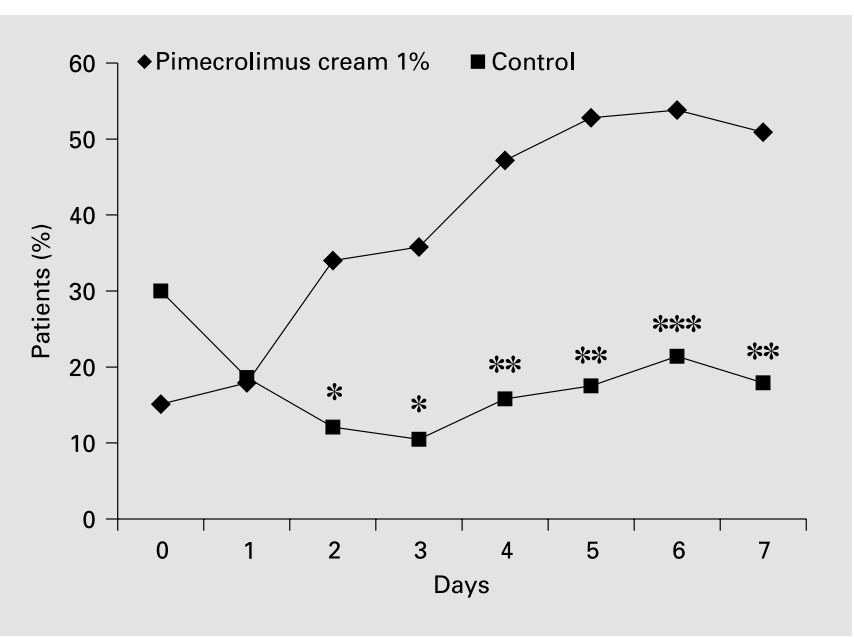

Fig. 3. Rapid relief of pruritus. ${ }^{* * *} \mathrm{p}<0.0001,{ }^{* *} \mathrm{p}<0.001,{ }^{*} \mathrm{p}<$ 0.01 (pimecrolimus vs. control). Pimecrolimus $n=51$, control $n=60$; pruritus relief defined as pruritus score of 0 (absent) or 1 (mild).

Table 2. Number of flares over 24 weeks (\%)

\begin{tabular}{|c|c|c|c|c|}
\hline \multirow[t]{2}{*}{$\begin{array}{l}\text { Number } \\
\text { of flares }\end{array}$} & \multicolumn{2}{|c|}{$\begin{array}{l}\text { Not including } \\
\text { discontinuations }\end{array}$} & \multicolumn{2}{|c|}{$\begin{array}{l}\text { Including } \\
\text { discontinuations }\end{array}$} \\
\hline & $\begin{array}{l}\text { pimecrolimus } \\
\text { cream } 1 \% \\
(\mathrm{n}=56)\end{array}$ & $\begin{array}{l}\text { control } \\
(\mathrm{n}=43)\end{array}$ & $\begin{array}{l}\text { pimecrolimus } \\
\text { cream } 1 \% \\
(\mathrm{n}=62)\end{array}$ & $\begin{array}{l}\text { control } \\
(\mathrm{n}=68)\end{array}$ \\
\hline 0 & 66.1 & 35.7 & 59.7 & 22.1 \\
\hline 1 & 10.7 & 16.7 & 9.7 & 10.3 \\
\hline 2 & 3.6 & 14.3 & 3.2 & 8.8 \\
\hline$\geq 3$ & 19.6 & 33.3 & 27.4 & 58.8 \\
\hline
\end{tabular}

\section{Quality of Life}

Quality of life improved rapidly and substantially in the patients treated with pimecrolimus cream $1 \%$. By the first post-baseline assessment at week 6, quality of life - as assessed by mean QoLIAD score - had improved by $25.5 \%$ in the pimecrolimus group, compared with only $2.1 \%$ in the control group $(\mathrm{p}<0.001)$. By week 24 (fig. 4), the mean QoLIAD score had improved by $34.9 \%$ in the pimecrolimus group, compared with $10.5 \%$ in the control group $(\mathrm{p}=0.002)$.

Similarly, the mean DLQI score at week 6 had improved by $25.3 \%$ in the pimecrolimus group, compared with a deterioration from baseline of $8.8 \%$ in the control group ( $\mathrm{p}<0.001)$. By week 24 (fig. 4), the mean DLQI score had improved by $22.9 \%$ in the pimecrolimus group, 


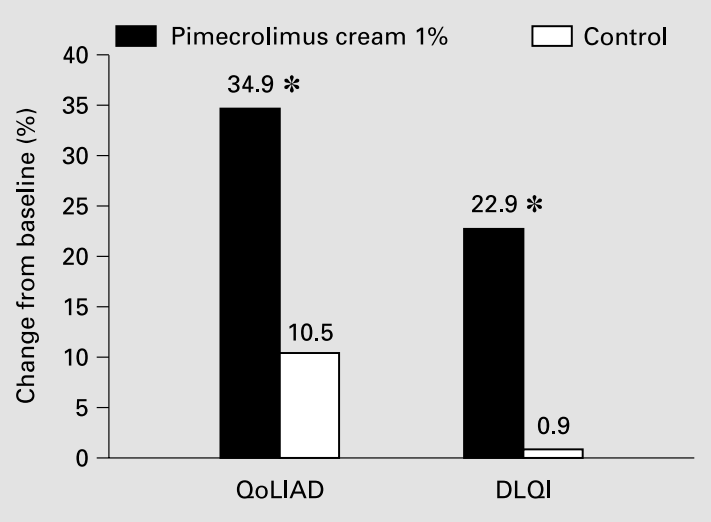

Fig. 4. Improvement in quality of life at 24 weeks. ${ }^{*} p<0.01$ (pimecrolimus vs. control).

Table 3. Number of patients with adverse events

\begin{tabular}{|c|c|c|}
\hline & $\begin{array}{l}\text { Pimecrolimus } \\
\text { cream } 1 \% \\
(\mathrm{n}=62)\end{array}$ & $\begin{array}{l}\text { Control } \\
(n=68)\end{array}$ \\
\hline Any adverse event & $46(74.2)$ & $51(75.0)$ \\
\hline Serious adverse events & $1(1.6)$ & $2(2.9)$ \\
\hline Skin infections & $13(21.0)$ & $8(11.8)$ \\
\hline Herpes simplex infections & $7(11.3)$ & $3(4.4)$ \\
\hline Eczema herpeticum & $0(0.0)$ & $1(1.5)$ \\
\hline Herpes simplex otitis externa & $0(0.0)$ & $1(1.5)$ \\
\hline Folliculitis & $0(0.0)$ & $1(1.5)$ \\
\hline Furuncle & $2(3.2)$ & $1(1.5)$ \\
\hline Erysipelas & $1(1.6)$ & $0(0.0)$ \\
\hline Stye & $0(0.0)$ & $2(2.9)$ \\
\hline Tinea pedis & $0(0.0)$ & $1(1.5)$ \\
\hline Skin infection NOS & $1(1.0)$ & $0(0.0)$ \\
\hline Withdrawals due to adverse events & $0(0.0)$ & $5(7.4)$ \\
\hline Drug-related adverse events & $14(22.6)$ & $16(23.1)$ \\
\hline $\begin{array}{l}\text { Application site reactions } \\
\text { (burning/erythema/pain/pruritus) }\end{array}$ & $9(14.5)$ & $6(8.8)$ \\
\hline \multicolumn{3}{|l|}{ Infections and infestations } \\
\hline Herpes simplex infections & $2(3.2)$ & $1(1.5)$ \\
\hline Eczema herpeticum & $0(0.0)$ & $1(1.5)$ \\
\hline Burning sensation & $2(3.2)$ & $2(2.9)$ \\
\hline $\begin{array}{l}\text { Unspecified lesions (acne/dermatitis/ } \\
\text { erythema/oedema/pruritus) }\end{array}$ & $1(1.6)$ & $10(14.7)$ \\
\hline
\end{tabular}

Results are numbers, with percentages in parentheses. NOS $=$ Not otherwise specified. compared with just $0.9 \%$ in the control group ( $\mathrm{p}=$ $0.007)$.

\section{Safety}

Pimecrolimus cream 1\% was well tolerated throughout the study. No patients in the pimecrolimus group, and only 3 patients in the control group, withdrew from the study due to adverse events. The only serious adverse event reported in the pimecrolimus group was a case of erysipelas that was considered to be unrelated to the study medication.

The overall incidence of drug-related adverse events in the pimecrolimus and control groups was similar (22.6 and $23.1 \%$, respectively) (table 3 ). Local application site reactions were the most common treatment-related adverse events. In total, 9 patients $(14.5 \%)$ in the pimecrolimus group and $6(8.8 \%)$ in the control group had a local application site reaction. Local tolerability was good, and application site burning was generally mild and transient, resolving within 1-7 days.

A total of 13 patients $(21.0 \%)$ in the pimecrolimus group and $8(11.8 \%)$ in the control group experienced a skin infection. Bacterial and fungal infections occurred at similar frequencies in both groups, but certain viral infections were more common in the pimecrolimus group. Specifically, 7 patients $(11.3 \%)$ in the pimecrolimus group, compared with $3(4.4 \%)$ in the control group, had an episode of herpes simplex infection. However, 4 of these 7 cases in the pimecrolimus group were herpes labialis (i.e. involving an area not treated by the study medication), compared with only 1 of the 3 cases in the control group. In total, 2 cases of herpes simplex in the pimecrolimus group and 1 in the control group were considered to be related to the study medication. No patient in the pimecrolimus group developed eczema herpeticum or herpes simplex otitis externa, compared with 1 case each in the control group.

No clinically relevant laboratory abnormalities were observed during the course of the study.

\section{Discussion}

This 6-month study in adult patients with moderate $\mathrm{AD}$ has demonstrated that the use of pimecrolimus cream $1 \%$, administered at the first signs or symptoms of an inflammatory exacerbation, prevents progression to flare and significantly reduces or eliminates the need for topical corticosteroids. Furthermore, long-term disease control is more effective with pimecrolimus cream $1 \%$, with 
fewer flares, a greater improvement in the signs and symptoms of AD and enhanced patient quality of life, compared with conventional therapy.

Approximately $60 \%$ of pimecrolimus-treated patients did not use topical corticosteroids at all during the entire 6 months and did not experience a single flare during this period. On average, the patients treated with pimecrolimus cream $1 \%$ used topical corticosteroids on $<10 \%$ of study days. The effects of treatment with pimecrolimus cream $1 \%$ on $\mathrm{AD}$ symptoms were rapid and sustained, with more than $50 \%$ of patients reporting either no or mild pruritus within 1 week of treatment initiation, and a reduction of $>70 \%$ in the median EASI score by week 24 . Treatment success, defined as an IGA score of 0 (clear) to 2 (mild disease), was achieved in more than $80 \%$ of the patients treated with pimecrolimus cream $1 \%$. These clinical benefits were associated with significant improvements in quality of life, as determined by two different assessment instruments, the QoLIAD and the DLQI.

Pimecrolimus cream 1\% was well tolerated and had a good safety profile throughout the study. Consistent with previous studies with pimecrolimus cream $1 \%$, the most common adverse event was application site burning, which was reported by $9(14.5 \%)$ of patients. Application site burning is generally a mild and transient reaction that resolves within a few days. No cases of application site burning led to withdrawal from the study.

It was notable that 7 cases of herpes simplex infection were observed in the pimecrolimus group during the course of the study, compared with 3 cases in the control group. This difference was not statistically significant and does not take into account the longer average time spent on the study by patients in the pimecrolimus group. Furthermore, 4 of these viral infections in the pimecrolimus group were herpes labialis infections, compared with only 1 in the control group. These infections occurred on the lips, which were unaffected by AD and untreated by the study medication; the imbalance in the incidence of herpes simplex is therefore most likely to have been a chance occurrence.

The results of this investigation are similar to those described in a previous report, which also included data for patients with severe disease at baseline [13]. The present report focuses specifically on moderate AD and demonstrates that pimecrolimus cream $1 \%$ is clinically highly beneficial in this more narrowly defined group. The results add to a growing data set from several clinical trials, showing that pimecrolimus cream $1 \%$ is consistently effective across a range of disease severities and has a good safety profile, demonstrating no clinically relevant systemic side-effects in $>5,000$ patients studied, from infants to adults $[13,18-21]$.

In conclusion, this study demonstrates that in adult patients with moderate $\mathrm{AD}$, long-term management with pimecrolimus cream $1 \%$ prevents flares in the majority of patients and even eliminates the reliance on topical steroids, improves the signs and symptoms of disease and enhances quality of life. The benefits of treatment were sustained over 6 months. These findings indicate that management with pimecrolimus cream $1 \%$ has the potential to significantly improve the long-term control of AD in patients with moderate disease.

\section{References}

1 Leung DY, Bieber T: Atopic dermatitis. Lancet 2003;361:151-160.

2 Rudikoff D, Lebwohl M: Atopic dermatitis. Lancet 1998;351:1715-1721.

3 Hill CJ, Rosenberg A Jr: Adverse effects from topical steroids. Cutis 1978;21:624-628.

4 McLean C, Lobo R, Brazier D: Cataracts, glaucoma, and femoral avascular necrosis caused by topical corticosteroid ointment. Lancet 1995;345:330.

5 Charman CR, Morris AD, Williams HC: Topical corticosteroid phobia in patients with atopic eczema. Br J Dermatol 2000;142:931-936.

6 Fukaya M: Why do patients with atopic dermatitis refuse to apply topical corticosteroids? Dermatology 2000;201:242-245.
7 Meingassner JG, Grassberger M, Fahrngruber H, Moore HD, Schuurman H, Stuetz A: A novel anti-inflammatory drug, SDZ ASM 981, for the topical and oral treatment of skin diseases: In vivo pharmacology. Br J Dermatol 1997; 137:568-576.

8 Hultsch T, Muller KD, Meingassner JG, Grassberger M, Schopf RE, Knop J: Ascomycin macrolactam derivative SDZ ASM 981 inhibits the release of granule-associated mediators and of newly synthesized cytokines in RBL $2 \mathrm{H} 3$ mast cells in an immunophilin-dependent manner. Arch Dermatol Res 1998;290:501507.

9 Grassberger M, Baumruker T, Enz A, Hiestand P, Hultsch T, Kalthoff F, Schuler W, Schulz M, Werner FJ, Winiski A, Wolff B, Zenke G: A novel anti-inflammatory drug, SDZ ASM 981, for the treatment of skin diseases: In vitro pharmacology. Br J Dermatol 1999;147:264-273.
10 Zuberbier T, Chong SU, Grunow K, Guhl S, Welker P, Grassberger M, Henz BM: The ascomycin macrolactam pimecrolimus (Elidel, SDZ ASM 981) is a potent inhibitor of mediator release from human dermal mast cells and peripheral blood basophils. J Allergy Clin Immunol 2001;108:275-280.

11 Queille-Roussel C, Paul C, Duteil L, Lefebvre M-C, Rapatz G, Zagula M, Ortonne J-P: The new topical ascomycin derivative SDZ ASM 981 does not induce skin atrophy when applied to normal skin for 4 weeks: A randomized, double-blind controlled study. Br J Dermatol 2001; 143:1-8.

12 Meurer M, Wozel G: The treatment of atopic dermatitis in adults with topical calcineurin inhibitors (in German). Hautarzt 2003;54: 424-431. 
13 Meurer M, Foelster-Holst R, Wozel G, Weidinger $\mathrm{G}$, Juenger M, Braeutigam M, CASM-DE01 Study Group: Pimecrolimus cream in the long-term management of atopic dermatitis in adults: A six-month study. Dermatology 2002; 205:271-277.

14 Rajka G: Natural history and clinical manifestations of atopic eczema. Clin Rev Allergy 1986;4:3-26.

15 Hanifin JM, Thurston M, Omoto M, Cherill R, Tofte SJ, Graeber M: The eczema area and severity index (EASI): Assessment of reliability in atopic dermatitis. Exp Dermatol 2001;10: 11-18.

16 Boehmer S, Naujoks C, Kohlmann T: Gesundheitsbezogene Lebensqualität - Entwicklung eines Fragebogens für Neurodermitis-Patienten. Hautfreund 2001;2:30-33.
17 Finlay AY, Khan GK: Dermatology Life Quality Index (DLQI) - A simple practical measure for routine clinical use. Clin Exp Dermatol 1994;19:210-216.

18 Wahn U, Bos JD, Goodfield M, Caputo R, Papp K, Manjra A, Dobozy A, Paul C, Molloy S, Hultsch T, Graeber M, Cherill R, de Prost Y, Flare Reduction in Eczema with Elidel (Children) Multicenter Investigator Study Group: Efficacy and safety of pimecrolimus cream in the long-term management of atopic dermatitis in children. Pediatrics 2002;110:e2.

19 Kapp A, Papp K, Bingham A, Foelster-Holst R, Ortonne JP, Potter PC, Gulliver W, Paul C, Molloy S, Barbier N, Thurston M, de Prost Y, Flare Reduction in Eczema with Elidel (Infants) Multicenter Investigator Study Group: Long-term management of atopic dermatitis in infants with topical pimecrolimus, a nonsteroid anti-inflammatory drug. J Allergy Clin Immunol 2002;110:277-284.
20 Eichenfield LF, Lucky AW, Boguniewicz M, Langley RG, Cherill R, Marshall K, Bush C, Graeber M: Safety and efficacy of pimecrolimus (ASM 981) cream 1\% in the treatment of mild and moderate atopic dermatitis in children and adolescents. J Am Acad Dermatol 2002;46:495-504.

21 Ho VC, Gupta A, Kaufmann R, Todd G, Vanaclocha F, Takaoka R, Foelster-Holst R, Potter P, Marshall K, Thurston M, Bush C, Cherill R: Safety and efficacy of nonsteroid pimecrolimus cream $1 \%$ in the treatment of atopic dermatitis in infants. J Pediatr 2003;142:155-162. 